\title{
The terminator syndrome: Science fiction, cinema and contemporary culture.
}

\author{
'... the myth of the man-machine is the \\ Ur-text of the late twentieth century ...'
}

(Mark Dery)

\begin{abstract}
This paper examines the impact of contemporany technology on representations of the human body in American popular culture, focusing on James Cameron's science fiction films The Terminator (1984) and The Teminator II - Judgment Day (1991) in both of which the key figures are cybernetic organisms (cyborgs) or a robot which can exactly imitate the human form. The paper argues that the ability of modem film technology to represent the human fonn in robotic guise undercuts the distinction between nature and culture which maintains the position of the hunsan being in society. The ability of the robot or cyborg to be 'polygendercd', in particular, undermines the position of a properly oedipalized human body in society, one which balances the instinctual life against the nule of cultural law. As a result the second Terminator film attempts a recuperation of the category of the human by an oedipalization of the terminator cyborg.
\end{abstract}

\section{Monsters and the body}

The body has long been considered a problematic and productive theme in Western art and knowledge; one which owes its central position in both traditions to the range of crucial questions and values which it seems to implicate. While this range of questions would be difficult to represent in all its variety, in essence concern with the body regularly raises the question of the place and role of the corporeal in the spiritual or cultural, or what it is that both connects and differentiates human beings from other living things. In other words, thinking upon the body always seems to act as a crucial indicator of the ways in which any given historical period (or philosophical position) conceives of the relationship between nature and culture.

While the content of this relationship has not always been thought in the same terms, it is clear that in any given culture a normalized conception of the body depends on a stable and differential relation of nature/culture, which is necessarily undermined by any alternative 
bodily form. Before the advent of the technological age (which introduces the first truly radical alternative body - the robot) the possibility of alternatives to the human body found dramatic enactment in the fascination with monstrosity.

The study of monsters, or teratology, reveals a complex variety of horrible and enchanting creatures, but it is nevertheless possible to distinguish between two kinds of monsters - the unique and singular, emphatically non-human or literal monster such as the dragon - and the kind of monsters which concern this paper - those which are a combination of the human and the non-human.

Early forms of monsters in this tradition include those which display alternative forms or distortions of an essentially human body (such as the races of savage men whose heads grow below their shoulders, inhabiting the outer rim of the world, or desert dwellers with one large foot for protection from the sun). However, the ones relevant here are those which have a mixed ontological status. In other words, those creatures, like centaurs, who are half human and half animal, half in nature and half in culture.

In contrast to their subsequent technological counterparts, such creatures, though anomalous, are not threatening to the relation between nature and culture because their bodies, while they have a mixed status, are always consistent. Thus, in the case of centaurs, they are always horses on the bottom and humans on top. Such consistency renders the monster non-threatening because it observes the stability of the nature/culture divide. These monsters are able to be understood, taxonomized, domesticated, 'gentled'.

An important indicator of the gentling of the monster is its ability to engender children, thus rendering it non-singular. Who, for instance, could fail to respond to the cuteness of the baby centaurs in Walt Disney's Fantasia? The concept is a fundamentally comforting one.

The fascination with the monstrous and the place of the body in culture, as well as the ambivalence about its status, reaches a kind of zenith in Mary Shelley's Frankenstein. Frankenstein's creature is a piece of nature created in culture. The violation which the young scientist thus accomplishes is an abomination purely because nature, imbued with secularized spirituality by Romanticism, has been superseded by culture in its most important and mysterious function - the creation of life.

This text is thus crucial not only as a culmination to a particular tradition of views of the monstrous, but also as the precursor to the preoccupation of the technological age with the intersection of science and knowledge in the body. It is this consideration which makes Frankenstein so widely regarded as the first work of science fiction (hereafter SF).

\section{Technology and the body}

For as long as it has been a part of culture, technology has held a special fascination for its admirers and detractors alike. Like monstrosity and thought on the body, it is a fascination in the proper sense - a fascination that is rooted in ambivalence towards its objects. These fascinations come together in what is one of the most characteristic, and certainly one of the most prevalent, objects of technological intervention - the human body. The body and technology intersect in most of the so called 'hard sciences', obviously including medicine 
but extending to include genetics, prosthetics, artificial intelligence and so on. Victor Frankenstein was consumed with what, at the beginning of the nineteenth century, must have seemed the ultimate possibility - that science and technology could create life.

In a famous passage in "Civilization and Its Discontents", Freud (1985:279-280) addresses the possibilities technology presents humanity, and points to the psychical needs technology might fill:

\begin{abstract}
With every tool man is perfecting his own organs, whether motor or sensory, or is removing the limits to their functioning. Motor power places gigantic forces at his disposal, which, like his muscles, he can employ in any direction; thanks to ships and aircraft neither water nor air can hinder his movements; by means of spectacles he corrects defects in the lens of his own eye; by means of the telescope he secs into the far distance; and by means of the microscope he overcomes the limits of visibility set by the structure of his retina. In the photographic camera he has created an instrument which retains the fleeting visual impressions, just as a gramophone disc retains the equally fleeting auditory ones; both arc at bottom materializations of ... his memory ... . These things that, by his science and technology, man has brought about on this earth, on which he first appeared as a feeble animal organism ... are a fulfilment of every - or of almost cvery - ... wish ... . . Man has, as it were, become a kind of prosthetic God. When he puts on all his auxiliary organs he is truly magnificent, but those organs have not grown onto him and they still give him much trouble at times.
\end{abstract}

Freud's extraordinarily prophetic words focus on the view that technology is an extension of the body, a tool in the body's service. But the functionality of technology is a double-edged sword - its powers far exceed what the body is capable of, and in its superiority to bodily instrumentality it presents the threat which Freud implicitly speaks to, the threat which Frankenstein and a long line of dystopian and technophobic SF warns against. This is nothing less than the extinction of nature by culture, technology run rampant in a future which would render the human body redundant, and with it the fragile enculturated identity of Freud's "feeble animal organism". Man might indeed "become a kind of prosthetic God", but the "auxiliary organs" technology provides for the attempt might replace the originals.

At the root of humanity's fascinated ambivalence with the body and technology is thus, on the one hand, what Freud (1984:315) rightly points to as the death drive, "an untiring impulsion towards further perfection" which manifests itself as the project to eliminate the error, failure and inconsistency the body, if it is human, is by definition subject to. On the other hand is the much less palatable possibility that the body as the locus of subjectivity and experience might become superseded.

It is the latter possibility which is explored by SF, a genre which explicitly deals with possible rather than actual events and objects. SF, in representing future possibilities, has long dealt with the kinds of changes technology might bring to bear on the body.

\title{
3. Robots and cyborgs
}

SF provides us with a particularly focused form of the 'body problem' in one of its favourite and most durable themes - the robot. For the purposes of this argument, I wish only to focus on the classical statement of SF's attitude to the robot rather than attempt to trace the history of the theme. That statement is Isaac Asimov's 'Three Laws of Robotics', drawn up in the so-called 'golden age' of SF. These 'laws' are as follows: no robot may allow a human being to come to harm; a robot must obey orders given by human beings, except where such orders conflict with the first law; and a robot must protect its own existence as 
long as this does not conflict with the first or second laws.

The influential Three Laws ${ }^{1}$ illustrate perfectly what the increasing possibilities of twentieth century technology put at risk - humanity. The Laws ensure that robots are servile to humans in stable and essential respects. Thus SF is here envisioning a future where a manifest danger to humans might come from robots, a technophobic outlook predominant in SF's view of the technology/body intersection. The trajectory of this fear culminates in the figure of the cyborg, the cybernetic organism which is the first to fully dramatize the human form as being of mixed ontological status. As Istvan Csicsery-Ronay puts it in a recent article (1991:395):

Historically, the cyborg has stood for the radical anxicty of human consciousness about its own cmbodiment at the moment that embodiment appears most fully contingent. Cyborg anxiety has stood for a panic oscillation between the "human" element (associated with affections, eros, error, innovations, projects begun in the face of mortality) and the "machinc" element (the desire for long life, health, physical impermeability, self-contained control processes, dependability, and hence the ability to fulfil promises over a long term). The classical SF cyborg is [thus] a sitc of panic psychology

Thus, 'cyborg anxiety' results from technological interference with what Freudian psychoanalysis would see as the constitution of a 'normal' human subject in society, which takes as fundamental the appropriate sexual organizations of the body.

The figure of the cyborg, then, represents the radicalized culmination of SF's appropriation of the theme of the body, and presents the intellectual and evaluative consequences of the changed ontological and psychological status of the body which technology appears to make possible.

In James Cameron's SF films The Terminator (1984) and its sequel, Terminator /I Judgment Dary (1991), the central figures are killer cyborgs, 'terminators', whose relentless quest is to kill the mother of the person who will lead human resistance to a future world order run entirely by machines. The dystopian scenario gives ample ground for a panic response. The terminator cyborgs of these films are representative of the body problem which this paper has sketched and which I have consequently called the terminator syndrome'.

\section{The terminator syndrome}

In the first Terminator film, a cyborg is sent back through time to kill the mother of John Connor, the human who will lead resistance to the rule of the machines in a dystopian postholocaust future.

The human resistance sends back a soldier to protect Sarah Connor from the cyborg. It is this soldier, who, before he dies protecting Sarah from the terminator, impregnates her with the son who will grow up to save his mother before he is conceived. The terminator

Asimov's Three Laws were first formulated in conversation with the famous SF magazine editor John W. Campbell, in the mid 1950s. They subsequently began to appear in most of Asimov's 'robot stories' of the late 1950s, and the 'robot novels' The Naked Sun (1957) and The Caves of Sieel (1958). 
cyborg, played by a typecast Arnold Schwarzenegger, is a 'classical' cyborg, a titanium alloy combat endoskeleton covered with living human tissue. In the course of the film, the human tissue gradually strips away due to shootings, car accidents, and so on, to reveal the naked and malevolent machine beneath (this process includes a famous sequence in which the cyborg, effecting self-repairs on its damaged body, inserts a scalpel into and removes its human eye, a la Dali and Bunuel's 'Andalusian Dogs'. With the kind of dark wit which characterizes both films, the cyborg then dons a pair of shades with the brand name 'gargoyles'!). The cyborg revealed as machine seems, as the soldier, Reese, tells Sarah Connor, to have no capacity for fear, pity or remorse. The difference between human outer appearance and machine inner reality reveals the cyborg as 'really' a machine, and thus reveals its violation of the stable inner/outer distinction which is one condition of a natural body.

The second Terminator film, made seven years after the first, sets out to confront a much more subtle set of technologically-posed problems. Here, the machines in the future have again sent back a terminator to kill John Connor, who is now about ten years old. This terminator, however, is an advanced prototype, the T-1000. The humans send back an old model terminator (again played by Schwarzenegger) to protect the young John Connor. The T-1000 is strictly speaking not a cyborg at all, but a robot, since it has no human components. It is made of a 'mimetic polyalloy', a sort of liquid metal which can imitate exactly any human form it has contact with. While it has no human components, the capacity of the T-1000 for imitation makes it much more threatening to the ontological status of the human than the cyborg proper, the Schwarzenegger model. Mark Dery (1992:103) specifies the nature of the threat:

The T-1000's quicksilver quality speaks loudly ... of mercury, a lunar, mutable element associated with androgyny and hermaphroditism. The robot is indeed polygendered: in its original state it is uncquivocally male, resembling an elfin-earcd Oscar or a Bauhausian dildo, but it can assume any sex.

It has been suggested previously in this paper that the enculturated body requires a zoned sexuality and the operation of taboos. It is these factors which maintain the balance between the instinctual life of the natural body and the subjection to laws of the encultured body.

The $\mathrm{T}-1000$ robot, by ignoring this frail distinction and changing with equal facility and believability from male to female and back, threatens perhaps the most important condition of the body in culture - that is, the relation of origin to end product, the infant becoming the properly oedipalized adult.

\section{SF, technology and the cinema}

The T-1000 goes through many radical changes in its appearance in the course of Terminator II - Judgment Day. The T-1000 robots are effected by a computer graphic technique called 'morphing', which is a computerese contraction of metamorphosis.

The powerful affect generated by the special effects technology in both films, but especially the morphing technique in the second, might be seen to have two causes. Firstly there is 
the very potent illusion of reality achieved by cinema through its fundamental technology every second, twenty four frames of celluloid run through a light shooting through a lens. The affective and psychoanalytic dimensions of this technology are fruitfully discussed by theorists like Stephen Heath and Christian Metz. ${ }^{2}$

Its effect is to make what is represented on the screen apparently occur in the same dimensions and space-time frame as reality. The use of special effects produces a spotty reputation and an easy critical target for the films which use them because they stretch this illusion of reality to its breaking point. Seen in an alternative light, the use of such special effects technology can be said to be simply more honest than films which eschew them in the service of realism, since the affect of the cinema is always a manifestly 'imaginary' one. The second cause of the powerful affect of the morphing technique, and the reason why SF films are on such intimate terms with special effects technology, therefore, comes from the fact that both $\mathrm{SF}$ and $\mathrm{FX}^{3}$ are committed to making the possible actual. The affect generated by morphing is because it actualizes, before the viewer's very eyes, a technological body being, strictly speaking, perverse - that is, polymorphous or at least 'polygendered'. The morphing technique thus enacts both the failure of the nature/culture divide and the triumph of its own technology as affective spectacles (though, in this case, silvered rather than rose-coloured).

\section{The terminator, Oedipus and the postmodern cyborg}

In 1985 (reprinted in 1990) the feminist biologist Donna Haraway published an essay which has subsequently become something of a cause celebre among postmodern theorists. Entitled "A Manifesto for Cyborgs", it posits a new form of hybridised existence between the human and the machinic, one which figures in contemporary culture through what Mark Dery (1992:103) calls the "micropolitical power-struggles of information", which centre on the body and its access to information on issues like AIDS treatment, surrogate mothering, genetic engineering, etc.

Haraway sees in the SF vision of a cyborg culture reason for hope in that it will liberate humanity from its enslavement to the power structures an oedipalized body fits into structures of capitalist production and patriarchy.

Haraway and other postmodernists like Jean Baudrillard (1991) maintain that such a scenario is upon us already in contemporary culture - the culture, as Baudrillard has it, of simulacra and hyperreality.

It is ironic then that a vast and sophisticated technological armature is used by a major event in contemporary popular culture - the second Terminator film - in order to recuperate the category of the human in the face of a superior technology. The first Terminator film left the terminator cyborg destroyed, but humanity facing an uncertain and probably apocalyptic future. In the second film, the vision of the future's possibilities

2 Sce, for example, Questions of Cincma (1980) by Heath and The Imaginary Signifier (1975) by Metz. 
seems to increase in rosiness for humanity in inverse proportion to the superiority of the film's technology. A major subtext in the film is the oedipalization of the Schwarzenegger terminator by the young boy John Connor. The terminator is programmed to develop human responses the longer he has contact with humans. The boy teaches the cyborg even to respond jokily to him, a major feat for an entity presumably without an unconscious in the usual sense.

As the boy's mother watches the child become father of the cyborgian man, she muses ironically that the terminator is the perfect father for the boy, one who would "never get drunk and hit him, would always be there for him", and that of all the men who had drifted through her life this was the best proposition. At the end of the film, in order to destroy the computer technology contained in its body which might give rise to a disastrous future for humanity, the terminator sacrifices itself nobly in a vat of molten steel. Sarah Connor reflects that "if a machine can learn the value of human life, maybe we can, too". It is a message of comfort to humanity, faced with the prospect of obsolescence, in which the category of the human is recuperated by making it transcendentally valuable.

\section{Conclusion: Who gets terminated, really?}

In the Terminator $I I$, therefore, the only good machine is an oedipalized one, who can be a father and learn the value of human life - a vision not very different from Asimov's Three Laws. Contrary to the view of postmodernism therefore, humanity, under ever-increasing pressure from technology, still seems to want a body that's alive and kicking.

\section{References}

Asimov, I. 1957. The Naked Sun. London : Granada.

Asimov, I. 1958. The Caves of Steel. London : Granada.

Baudrillard, J. 1991. Simulacra and Science Fiction. Science Fiction Studies part 3, 55(18):309-313, November.

Csicsery-Ronay, I. 1991. The SF of theory: Baudrillard and Haraway. Science Fiction Studies part 3, 5S(18):387-404, November.

Dery, M. 1992. Cyborging the Body Politic. Mondo 2000: 6:101-105

Haraway, D. 1990. A Manifesto for Cyborgs. In: Nicholson, L. (ed.) Feminism Posımodenism. London : Roulledge. p. 190-233.

Heath, S. 1980. Questions of Cinema. London : Macmillan.

Freud, S. 1984. Beyond the Pleasure Principle. In: On Metapsychology. Harmondsworth : Penguin. p. 275-338.

Freud, S. 1985. Civilization and its Discontents. In: Civilization, Society and Religion. Harmondsworth : Penguin. p. 251-340.

Metz, C. 1975. The Imaginary Signifier. Oxford : Oxford University Press.

Shellcy, M. 1985. Frankenstein. Harmondsworth : Pcnguin.

\section{Vista University (Daveyton)}


